\title{
Two Shared Cataloging Data Bases: A Comparison
}

\begin{abstract}
The Ohio College Library Center (OCLC) and Blackwell North America (B/NA) have data bases used by many libraries to produce catalog copy. These data bases are compared for availability of cataloging for English language books. Although OCLC provides cataloging for a larger percentage of titles, the B/NA data base produces a high enough percentage of hits to be very valuable. The greater number of titles available through OCLC is attributable to the larger group of contributors, not necessarily to quality of the data base. The difference in cost between the two systems and the comparable peripheral services available make utilization of B/NA data base appealing.
\end{abstract}

$\mathrm{T}$ Te "Annual Buyers' Guide" in the September 1, 1975, issue of Library Journal lists twelve vendors which provide cataloging services. ${ }^{1}$ Not included in the list are three other commercial vendors and all of the various noncommercial cataloging centers, such as the Ohio College Library Center (OCLC). Of this total there are six commercial services with data bases comparable to the OCLC data base. However, five services (BroDart, Baker \& Taylor, Library Processing Systems, Telemark of Josten's, and CARDSET of Information Design) have automated data bases containing essentially cataloging records based on the MARC distribution services. Some of these services (CARDSET, for example) provide access to more extensive files. This access is usually via some nonautomated technique such as microform editions of NUC

R. W. Meyer is director of library technical services, Indiana State University, Terre Haute; and Rebecca Panetta is chief of book processing, The University of Texas at Dallas. with special indexes. Only BIBNET and B/NA Technical Services compare to OCLC in the approach to their development and utilization.

The BIBNET System of 3M Corporation (formerly a product of Information Dynamics, Inc.) and the Title Index of Blackwell North America, Inc. (B/NA), both contain those records distributed by MARC plus other contributed records. The BIBNET system, however, primarily adds non-MARC records based on MCRS (Micrographic Catalog Retrieval System) records selected by users. BIBNET is an online system like OCLC, but, instead of the user adding records on line, additions are requested by users and added by BIBNET staff. Because there is no basis of experience with the BIBNET system at the library of the University of Texas Dallas (UTD) no further comparison is made here. Based on direct experience with both B/NA and OCLC, this paper reports a snapshot comparison of these two data bases as sources of cataloging copy. Since these are two of the largest shared cataloging data bases, this 
seems to be a useful comparison. Similar peripheral aspects of the two systems are also briefly compared here.

\section{Data Base Descriptions}

From early 1971 through April 1974 the UTD library acquired its catalog copy by searching the Richard Abel Co. (selected assets of Abel were acquired by $\mathrm{B} / \mathrm{NA}$ in January 1975) data base via the $B / N A$ Title Index and requesting cards by LC card number or B/NA card number. The library retains a subscription to the B/NA Title Index for original cataloging of nonprint media not yet available on OCLC and for some preorder search verification.

The library joined the OCLC system with the Amigos Bibliographic Council network in April 1974. Since then, all cataloging of monographs has been produced via OCLC.

The Ohio College Library Center (OCLC) data base contains over 2,100,000 entries as of April 1976 in the MARC format, of which some 65 percent are user contributed. As of April 1976 the OCLC data base is accessible by CRT terminal on-line 7:00 a.m. to 10:00 p.m. Eastern time Monday through Friday and 8:00 a.m. to 8:00 p.m. Eastern time on Saturday. The terminal user can find a cataloging record by keying in, on a typewriter-like keyboard, algorithms representing the title, author/title, or author of a book, or the LC card number. After, occasionally, some further dialogue, the terminal screen displays a complete cataloging record in an expanded MARC format.

The Blackwell North America basic data base contains over 1,164,000 entries as of April 1976, of which approximately 40 percent are user contributed. The $\mathrm{B} / \mathrm{NA}$ data base is accessible via a Computer Output Microfiche (COM) Title Index. The Title Index is completely regenerated quarterly and is updated biweekly with a cumulative supplement. Each entry in the index displays title, author, imprint, LC card number, B/ NA card number, the source of the cataloging copy, and source of the MARC record. A new format which began May 1, 1975, also shows collation, ISBN, and LC and Dewey class numbers.

Both data bases contain virtually all the MARC records for monographs and for serials. Both are routinely updated as MARC tapes are received. Entries contributed to OCLC by member libraries are input directly on-line. This input costs the user nothing except staff time and $\$ 0.037$ per card produced. Contributed copy to B/NA costs $\$ 2.00$ to be input into the system, and this includes the cost of the card set. Cost of cataloging copy retrieved from $\mathrm{B} / \mathrm{NA}$ will vary depending on the source of the MARC copy and the method of access. ${ }^{2}$ The B/NA data base contains a lower percentage of duplicate entries because all contributed entries are pre-edited by a central staff.

The OCLC data base has a larger group of contributors, so it is growing at a faster rate, but little central control over contributed entries is maintained, i.e., duplicates are deleted by central staff only after detection by users. Before a library can effectively participate in OCLC, it has been suggested that it should have an annual acquisition rate of at least 2,500 titles. $\mathrm{B} / \mathrm{NA}$ requires no minimum acquisition rate. The practical minimum annual cost of tying into OCLC is approximately $\$ 4,000.00$. A subscription to the Title Index is currently $\$ 680.00$ per year plus the cost of card sets purchased.

These figures for tying into OCLC of 2,500 titles and $\$ 4,000.00$ are not absolute, but they have been suggested as guidelines to potential participants. They will vary depending on contract terms and the approach to utilization by the individual library. B/NA reports that only 10 percent of its users subscribe to the Title Index, and 90 percent 
order cataloging by LC card number, ISBN, or author/title, thus eliminating need for a subscription.

\section{Cataloging Operations}

The amount of time needed to train personnel to search on either system is about the same. The use of OCLC seems more complicated than a microfiche search at first glance. But because the $\mathrm{COM}$ programs employed to produce the B/NA Title Index result in a different sort sequence than most libraries use in card filing, some staff training is necessary. Computers have been improved in their ability to produce sophisticated filing sequences, but some familiarity with computer sorting is required before effective searching is possible. The reader is referred to the preface of Books in Print or to Library of Congress Catalogs: Films, 1974 for some interesting reading on computer filing. ${ }^{3}$ Using a microfiche reader does not offer the same initial excitement as using an on-line terminal, and eagerness to learn about computerized cataloging usually facilitates training on OCLC.

The use of the Title Index for cataloging required a routine which, at UTD, included an area of shelving designated for books for which cataloging had been ordered. Each title was individually searched against the $\mathrm{B} / \mathrm{NA}$ Title Index, and when located the LC card number and $\mathrm{B} / \mathrm{NA}$ card number were listed. For new titles with late LC card numbers (prefix of 69 or higher), the Title Index search was skipped, and the LC card number was listed. The books were then set aside in LC card number order. (Since LC and Dewey class numbers now appear in Title Index entries, it would be possible to process titles immediately and merely retain a P-slip for control.) Books without late LC card numbers and not located were set aside for future searching or original cataloging. The list of $\mathrm{B} / \mathrm{NA}$ card numbers and LC card numbers was then submit- ted to $\mathrm{B} / \mathrm{NA}$ with a request for card sets.

Catalog card sets from B/NA usually arrived at UTD from one to three weeks after being ordered. These sets included all the necessary entry headings but had to be sorted into author, title, shelflist, and subject groups before filing. (B/NA has offered a presorting service since mid-1975.) Any needed additions and changes to the catalog copy had to be made after receipt of cards. However, users can now modify any record supplied by sending modified unit cards, or worksheets, or field-updates with card orders. With this fieldupdate service for each library, B/NA is thus able to preserve local practices and ensure that master MARC records remain true to LC practice as a minimum standard of bibliographic control.

Cataloging monographs on OCLC is accomplished via the following routine at UTD. Books are searched on the terminal. If found, the call number is marked in the book, and the book is processed. Any editing of the record, e.g., change of call number, is made before producing cards. Books not found are set aside to be searched again or for original cataloging. A daily record of cards produced is kept by filing, in shelflist order, P-slips for all titles processed. Cards arrive in about ten days, and all cards produced on the same day arrive together. Cards come presorted and prefiled into shelflist, author, title, and subject packs. A brief check of the shelflist cards against the P-slips is made before filing in order to double check for errors and possible losses in the mail. It should be noted here that UTD also receives from OCLC the same bibliographic information that the cards contain in the form of MARC records on magnetic tape. These are utilized to produce a computer output microform (COM) catalog. This is explained in detail elsewhere. ${ }^{4}$

Actual time of receipt of cataloging 
copy varies from both sources. OCLC hypothetically prints cards the night of the day they are requested, but experience has shown their scheduling to slip on occasion. Cards are usually received within ten days. For cards ordered from $\mathrm{B} / \mathrm{NA}$, time of receipt varies from one to three weeks depending on the mail both ways and on batch queuing of requests.

\section{COMPARISON}

To compare the availability of catalog copy on the two data bases, the following study was made. Three sample sets selected from current imprints were gathered from approval books received from B/NA in July, August, and October of 1974. The samples were limited to English language imprints, because MARC records at that time included English language only. Sample sizes were based only on the size of approval shipments received. Each sample was searched twice at an interval of about two months. Search time of each data base averaged thirty titles per hour. This included time to alphabetize P-slips or books by title when searching the Title Index. The Title Index is actually faster to search because there is no dependence on response time or computer down time. Searches on OCLC were made by LC card number when available and title or author/title when necessary. Ability to search OCLC by more than just title may have resulted in a bit better hit rate except that this was obviated because all items were monographs with reasonably straightforward titles. Search time on OCLC varied depending on time of day and the status of the system during the search period. The increase in subscribers to OCLC affected the response time of the system negatively, but the addition of more computing equipment has improved the situation.

There were a total of 344 titles in the three samples searched. Table 1 gives a summary view of these samples, showing that most of the titles were published in the U.S. in 1974 and included LC card numbers. Presumably, MARC records were available for many of the titles. Since the books were supplied by $\mathrm{B} / \mathrm{NA}$, it would seem the study might be slanted toward B/NA. Interestingly, however, OCLC demonstrated a higher percentage of hits in each of the three samples. Altogether, 274 titles (72 percent) were located in the B/NA Title Index; 315 (92 percent) in OCLC; and 232 (67 percent) were listed in both. Only fourteen titles were located in neither data base.

TABLE 1

Distribution of Sample of Titles and Location in B/NA and OCLC Data Bases By Place of Publication, Imprint Date, and Presence of LC Card Number

\begin{tabular}{|c|c|c|c|c|c|}
\hline \multirow{2}{*}{ Place of Publication } & $\begin{array}{c}\text { Total Sample } \\
\text { Number }\end{array}$ & \multicolumn{2}{|c|}{$\begin{array}{l}\text { Located in B/NA } \\
\text { Number }\end{array}$} & \multicolumn{2}{|c|}{$\begin{array}{c}\text { Located in OCLC } \\
\text { Number }\end{array}$} \\
\hline & & & & & \\
\hline U.S. & 267 & & 76 & 258 & $\begin{array}{l}97 \\
80\end{array}$ \\
\hline Other & 21 & $\begin{array}{l}33 \\
10\end{array}$ & $\begin{array}{l}59 \\
48\end{array}$ & $\begin{array}{l}45 \\
12\end{array}$ & $\begin{array}{l}80 \\
57\end{array}$ \\
\hline $\begin{array}{l}\text { Totals } \\
\text { Date of Publication }\end{array}$ & 344 & 247 & 72 & 315 & 92 \\
\hline \multicolumn{6}{|l|}{ Date of Publication } \\
\hline $\begin{array}{l}1972 \\
1973\end{array}$ & & & 100 & 2 & 100 \\
\hline $\begin{array}{l}1973 \\
1974\end{array}$ & $\begin{array}{r}45 \\
297\end{array}$ & 218 & $\begin{array}{l}60 \\
73\end{array}$ & $\begin{array}{r}37 \\
276\end{array}$ & $\begin{array}{l}82 \\
93\end{array}$ \\
\hline $\begin{array}{l}\text { Totals } \\
\text { LC Card Number }\end{array}$ & 344 & 247 & 72 & 315 & 92 \\
\hline \multicolumn{6}{|l|}{ LC Card Number } \\
\hline $\begin{array}{l}\text { Present in book } \\
\text { Absent }\end{array}$ & $\begin{array}{r}274 \\
70\end{array}$ & $\begin{array}{r}210 \\
37\end{array}$ & 77 & 264 & $\begin{array}{l}96 \\
73\end{array}$ \\
\hline $\begin{array}{l}\text { ADsent } \\
\text { Totals }\end{array}$ & 344 & 247 & 72 & 315 & 92 \\
\hline
\end{tabular}


Six months after the original searches were completed, a new search was conducted for these fourteen titles. Thirteen were then available in OCLC and seven in B/NA. From this it seems that both data bases will eventually contain cataloging records for even obscure English language titles; but OCLC with its many contributors is able to produce them sooner.

The basic advantage, then, of the OCLC system is the availability of cataloging for more publications, particularly non-MARC titles. Table 1 shows a listing of the titles located in each of the data bases by place of publication, date of publication, and presence or absence of LC card number. For example, there were seventy titles that did not include LC card numbers. Of this total, thirty-seven ( 53 percent) were located in $\mathrm{B} / \mathrm{NA}$, and fifty-one (73 percent) were located in OCLC.

In the original searches of the samples, OCLC was able to provide cataloging for more of the titles initially, but most of these were found in the Title Index in later searches. Those found originally in the Title Index, but not on OCLC, were all available on OCLC by the time of the second search. Searching for MARC records produced equal results, for as MARC tapes were added to OCLC, supplements to the Title Index arrived, usually at about the same time. On occasion, because of technical problems, OCLC has held MARC tapes and added two or three in one week. This delays cataloging operations somewhat, but no major problems are apparent. Having once searched the Title Master for a title, one need check only the supplement in future searches during that quarter of the year. Search time on OCLC varies with the time of day during which the system is being used. For example, early in the morning, late in the afternoon, during the evening, and on Saturdays response time is faster because there are fewer users.

\section{Peripheral Aspects}

Neither B/NA nor the OCLC System is designed to be used exclusively for the generation of catalog cards. Part of the underlying philosophy of OCLC is to reduce the rate of increase in per-unit processing costs for libraries by sharing the work load. This same philosophy works with $\mathrm{B} / \mathrm{NA}$ also, though less well since there are fewer users sharing the burden. Both systems also attempt to provide for other library operations.

Both systems provide some acquisition help. OCLC is in the process of designing a complete acquisition package which would allow users to generate and keep track of orders through the system. Total implementation of the system is probably some years off, but the data base already provides a point for preorder search verification. The Title Index also provides a source for preorder searching, but this is of a different nature since no indication is given in the Index as to which users already have cataloged (thus own) specific titles, as does the OCLC system. A glance at the holding library symbols on an OCLC record shows immediately which institutions have cataloged the item

Because of this last capability of OCLC there is the obvious, and well used, spin-off feature of interlibrary loan information. By searching OCLC's data base, one can tell which institutions have cataloged any specific title; thus interlibrary loan requests can be made with prior knowledge that the loaning institution will be capable of supplying the book. OCLC will soon add a communications capability to facilitate ILL further.

OCLC is in the last phase of implementing a serials control system for users which provides for check-in, claiming, and binding as well as cataloging. This is due for full implementation during 1976. B/NA provides no help for serials beyond cataloging.

$\mathrm{B} / \mathrm{NA}$ provides along with catalog 
copy, to any user who desires them, circulation materials. These can be spine labels, pockets, circulation cards, label sets, IBM cards, or whatever is required. Books ordered from B/NA can be purchased preprocessed or with complete processing kits.

OCLC provides no help with circulation or processing, although a complete circulation control system is planned. OCLC is also in the process of developing a subject retrieval component of a public service system which may be tested in 1976. B/NA does not provide subject retrieval on its full data base but can generate $\mathrm{COM}$ or printed subject catalogs for any user. B/NA can also provide subject bibliographies from any of its data bases.

This subject capability of $\mathrm{B} / \mathrm{NA}$ is part of the overall data base management available for their users. B/NA programs keep track of every record used in or contributed to B/NA. The production of complete or partial book catalogs is thus possible at any time for any user by employing programs developed by $\mathrm{B} / \mathrm{NA}$. These catalogs can be printed or produced on COM in any number of formats and with cumulative supplements. Complete subject authority control is also part of the system. The important aspect of the B/NA system is the total management control over each user's subset of records within the $\mathrm{B} / \mathrm{NA}$ data base and the production of viable products from this system in addition to traditional catalog cards.

OCLC as yet provides in addition to catalog cards only archival tapes of rec- ords used by individual institutions in the sequence used and with no duplicates deleted. It is a long step from this tape service to data base management for individual institutions.

\section{Conclusion}

Both data bases are very useful. Although access differs, both can be used effectively to generate catalog copy. From 62 to 76 percent of the titles searched were found in the $\mathrm{B} / \mathrm{NA} \mathrm{Ti}$ tle Index, and from 76 to 98 percent were found in OCLC. This appears to make OCLC significantly more valuable. The higher hit percentage is accounted for by the greater number of contributed records since both contain the same MARC records. The acceptability of the contributed records, of course, depends on the degree to which the contributors meet the standards.

During the interval between searches the number of records available in the OCLC data base increased more than in the B/NA Title Index. Some sort of logical extrapolation of this increase would imply that it will be an obscure item that doesn't appear in OCLC eventually.

For the cataloging of English language monographs the OCLC data base is a very valuable tool; so is the Title Index. In view of the cost of tying into OCLC versus the cost of subscribing to $\mathrm{B} / \mathrm{NA}$ service, the microfiche system can appear very appealing where budgets are small or acquisitions rates moderate or where total data base management is required.

\section{REFERENCES}

1. “Annual Buyers' Guide," Library Journal 100:1500 (Sept. 1, 1975). See also Nancy Hoyt Knight, "Microform Catalog Data Retrieval Systems: A Survey," Library Technology Reports 11 (May 1975), and Howard Pasternack, "Microform Catalog Data Retrieval Systems: The B/NA Title Index and MARCFICHE Systems," Library Technology Reports 12:371-405 (July 1976).

2. Blackwell North America, Inc., "1974/75
Pricing for Cataloging and Book Processing Services." Available from B/NA, 10300 S.W. Allen Blvd., Beaverton, OR 97005.

3. Books in Print (New York: Bowker, 1975), V.1, preface. U.S. Library of Congress, Films and Other Materials for Projection, 1974 (Washington, D.C., 1975), p.vii-viii.

4. R. W. Meyer and John Knapp, "COM Catalog from OCLC Records," Journal of $\mathrm{Li}$ brary Automation 8:312-21 (Dec. 1975). 